\title{
Looking back for the future
}

\section{Dong-Wook Song ${ }^{1}$}

Published online: 20 March 2020

(C) World Maritime University 2020

The very first editorial of WMU Journal of Maritime Affairs (JOMA) in 2002 states that:

The basic objective of the Journal is to present fresh ideas and current thinking on pertinent issues in these subject areas [these being maritime safety, maritime environment, and shipping operations with special attention to the human element and impact of technology ], which are of interest to a wide range of professionals from maritime administration, industry and education world-wide. With due regard to intellectual rigor and academic standards, we shall therefore strive to present ideas and arguments in the Journal which are not unduly esoteric or theoretical. (Laubstein 2002, p. 1)

When reading this statement for the first time as an editor-in-chief: a duty assigned to me in the early last year, I did immediately think of a few ways to examine what impact has been made by the Journal on the field (practically as well as theoretically). A chosen way was to conduct a bibliometric analysis of all those articles appeared at JOMA since its first issue published in 2002. While acknowledging that the chosen one might not be the best option, I would sense that its findings were able to show us an aspect of the impacts that the Journal was expected to make as indicated in the first editorial.

Thanks to the two colleagues of mine, Dr Satya Sahoo and Dr Alessandro Schönborn, we are now able to see the impacts as presented at the first paper of the current issue. Their study (Sahoo and Schönborn 2020) provides a reflection on the Journal's aim from the perspective of its original mission and offers some insights into its holistic picture to represent the maritime field in a broad term. Their findings are that such research areas as Maritime Safety, Maritime Education and Training, Maritime Law Policy and Governance, and Environmental Impact of Maritime Activities have traditionally accounted for a large share of JOMA's articles. The Journal has, however, managed to keep a tradition of not letting one area of research dominate over the others from a holistic perspective. Furthermore, they make a concluding remark that, while the

Dong-Wook Song

joma@wmu.se

1 Shipping and Port Management, World Maritime University, Malmö, Sweden 
research areas of Environmental Impact of Maritime Activities (EIMA), Maritime Safety (MS), Maritime Education and Training (MET), Maritime Energy Management (MEM), Maritime Economics and Business (MEB), and Maritime Law, Policy and Governance (MLPG) remain and sustain a healthy trend, the Journal is required to take action and/or measures to enhance an impact of those areas of Maritime and Marine Technology and Innovation (MMTI) and Maritime Social and Labour Governance (MSLG).

I am personally pleased to see their results and, at the same time, obliged to do something as per their suggestions. A number of measures could be considered as a potential option to get improved an impact of a journal like JOMA. Your editor-in-chief promises the JOMA readerships that all those measures would be put into an editorial 'equation' in a way to find an optimal solution for a short-, medium- and long-term impact of the Journal. Below are just some thoughts to be put into action this year:

- Writing a series of editorial over the issues to come having clearly indicated an expectation from future authors, reviewers, and editorial board members. These include such topics as 'how to get your paper(s) published at referred journal like JOMA', 'how to review a manuscript in a constructive manner for JOMA', and 'how reviewing and editorial procedures are conducted in JOMA'.

- Reshuffling and/or updating editorial board members in line with the Journal's aim and direction. For this matter, a number of professionals (in academic communities and industrial sectors) will be consulted.

- Launching such awards as an annual 'Best Paper Award' and 'Best Reviewer Award' from this year and announcing those awardees at the first issue of 2021 as a starter.

- Inviting authoritative researchers, policy makers, and industry voices in a field falling into JOMA's research domains to produce an article as an invited paper. Those who are highly recognised in the bibliometric paper of this issue would be obvious candidates to be invited.

- Creating a 'Book Review' section and introducing recently published books by offering a review by discipline experts.

- Strengthening the Journal's tie with the IAMU community by making fine-tuning exercises with its section editor and management team.

These are the ones that come into the mind of your editor-in-chief, who is naturally looking forward to receiving any comments and feedbacks from the Journal readerships. Please drop him an email whenever you feel it could be helpful and useful to the common good of your journal-JOMA.

Thank you for your active participation in anticipation and enjoy reading the first issue of the year 2020 .

Your editor-in-chief,

Dong-Wook Song

joma@wmu.se 


\section{References}

Laubstein K (2002) WMU Journal of Maritime Affairs - Editorial 1(1):1

Sahoo S, Schönborn A (2020) A bibliometric overview of WMU Journal of Maritime Affairs since its inception in 2020. WMU J Marit Aff 19(1):1-21. https://doi.org/10.1007/s13437-020-00197-w

Publisher's note Springer Nature remains neutral with regard to jurisdictional claims in published maps and institutional affiliations. 